\title{
Vibration Interaction Analysis of Non-uniform Cross-Section Beam Structure under a Moving Vehicle
}

\author{
Masoud Asgari \\ Faculty of Mechanical Engineering, K. N. Toosi University of Technology, Pardis Street, Molla-Sadra Avenue, \\ Vanak Square, Tehran, Iran
}

\begin{abstract}
(Received 27 August 2014; accepted 17 November 2014)
One of an engineer's concern when designing bridges and structures under a moving load is the uniformity of stress distribution. The dynamic behavior of a vehicle on a flexible support is also of great importance. In this paper, an analysis of a variable cross-section beam subjected to a moving load (such as a concentrated mass), a simple quarter car (SQC) planar model, and a two-axle dynamic system with four degrees of freedom (4DOF) is carried out. The finite element method with cubic interpolation functions is used to model the structure based on the Euler-Bernoulli beam and a direct integration method is implemented to solve time dependent equations implicitly. The effects of variation of a cross-section and moving load parameters on the deflection, natural frequencies, and longitudinal stresses of the beam are investigated. The interaction between vehicle body vibration and the support structure is also considered. The obtained results indicate that using a beam of parabolically varying thickness with a constant weight can decrease the maximum deflection and stresses along the beam while increasing the natural frequencies of the beam. The effect of moving mass inertia at a high velocity of a moving vehicle is also investigated and the findings indicate that the effect of inertia is significant at high velocities.
\end{abstract}

\section{INTRODUCTION}

The analysis of structures carrying moving loads is of considerable practical importance. Bridges on which vehicles or trains travel, trolleys of cranes that move on their girders, and many modern machining operations, such as high-speed precision drilling, can be modeled as a moving load problem.

Since the middle of the last century, when railway construction began, the problem of oscillation of bridges under traveling loads has interested engineers. Contributions towards a solution of this problem were initially made by Stoke $^{1}$ and Robert Willis. ${ }^{2}$ Timoshenko ${ }^{3}$ found an analytical solution for the case of a concentrated force moving with a constant velocity along a beam, neglecting the damping effect.

A comprehensive treatment of the subject of vibrations of structures due to moving loads that contain a large number of related cases is that of Fryba. ${ }^{4}$ In a dynamic analysis of structures subjected to moving loads involving a large moving mass, neglecting inertia may cause a considerable error. When the mass of either the moving load or the structure cannot be ignored, the dynamic analysis of moving load problems becomes more involved. The first attempt to include the mass of both the beam and the moving load was given by Jefcott. ${ }^{5}$ Calculating the response of beams affected by moving mass involves solving sufficiently complex partial differential equations that the analytical methods are not almost applicable. Therefore, the numerical methods have been used frequently to solve various boundary conditions and complicated cases such as variable speed moving load, multiple span beam, damping within the beam, sprung mass, et cetera. Akin and Mofid ${ }^{6}$ developed an analytical-numerical method to determine the behavior of beams carrying a moving mass. Esmailzadeh and Ghorashi ${ }^{7}$ analyzed the Timoshenko beam traversed by a uniform partially distributed moving mass. Esmailzadeh and Jalili ${ }^{8,9}$ investigated the dynamic interaction of moving vehicles on uni- form suspension bridges. They modeled the vehicle as a halfcar planar model with six degrees of freedom.

The finite element method was applied to overcome some of the limitations in analytical analysis. The finite element method was first used by Cook and Fleming. ${ }^{10,11}$ Filho $^{12}$ surveyed the application of the finite element method as a simply supported beam subjected to a constant-velocity two degrees of freedom system with various mass ratios. Lin and Trethewey ${ }^{13}$ analyzed the dynamics of an elastic beam that was subjected to dynamic loads induced by the arbitrary movement of a springmass-damper system, which was based on a finite element formulation and solved it with a Runge-Kutta integration scheme. The analysis of a beam with a non-uniform cross-section was completed by Gutierrez and Laura. ${ }^{14,15}$ It dealt with the approximate determination of the vibration of a beam traversed by a time varying concentrated force. Zheng et al. ${ }^{16}$ studied the vibration behavior of a multi-span continuous bridge modelled as a multi-span non-uniform continuous Euler-Bernoulli beam under a set of moving loads using different assumed mode shapes. Wu and Dai ${ }^{17}$ and Henchi and Fafard ${ }^{18}$ used the same Euler-Bernoulli beam and the finite element transfermatrix approach.

Ahmadian et al. ${ }^{19}$ also considered the analysis of a variable cross-section beam subjected to a moving concentrated force and mass by using the finite element method. Dyniewicz ${ }^{20}$ dealt with the vibrations of structures subjected to a moving inertial load using the velocity approach to the space-time finite element method. Zhai and Song ${ }^{21}$ were concerned with the transient vibration analysis of the railway-ground system under fast moving loads formulating a 3D finite element method in a connected coordinate system moving with the load together with viscous-elastic transmitting boundary conditions in order to limit the finite element mesh. Azizi et al. ${ }^{22}$ employed the spectral element method in a frequency domain to analyze continuous beams and bridges subjected to a moving load. Samani 


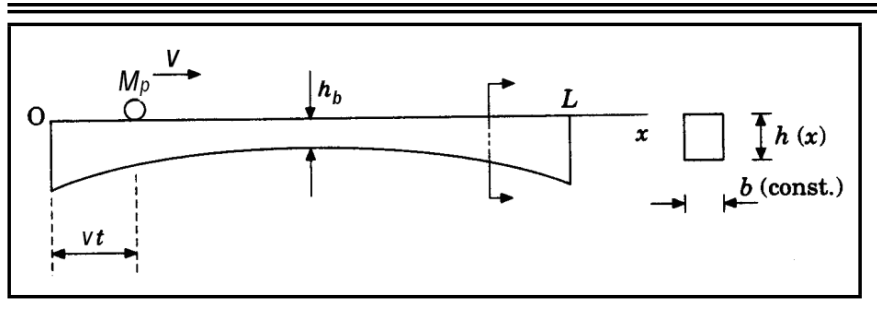

Figure 1. A simply supported non-uniform cross-section beam subjected to a moving point mass.

and Pellicano ${ }^{23}$ focused on the analysis of the effectiveness of dynamic vibration absorbers applied to beams excited by moving loads. They also assessed the performances of dynamic vibration absorbers in suppressing the vibrations of a simply supported beam subjected to an infinite sequence of regularly spaced concentrated moving loads. ${ }^{24}$

Most of these studies for the moving load problem were limited to the beam of a uniform cross-section and the beam of a non-uniform cross-section that neglected the inertia effect of the moving load. The solution of a general moving load problem remains of considerable interest and engineering applicability. In order to perform a detailed design and optimization analysis, a general solution technique must be developed for many complicated cases. As an extension to these works, the present paper deals with the problem of a non-uniform crosssection beam with different boundary conditions subjected to moving loads, such as a moving concentrated mass, a simple quarter-car (SQC) planar model, and a two-axle dynamic system with four DOF by developing the derivation of characteristic equations and including effect of structural damping and moving load inertia on the beam. Additionally, the dynamic deflection of the beam, the critical speed of the moving vehicle, and the distribution of maximum longitudinal stress along the beam was considered. The contact between load and support beam during movement was checked by considering the value of the interaction force between them. For the initial condition, the beam was considered to be at rest.

\section{PROBLEM FORMULATION}

For the purpose of this investigation, we began from a simple system and progressed to more complex ones. Three different cases will be presented: the concentrated moving mass problem will first be reviewed, the simple quarter-car model will then be investigated by the proposed method, and lastly the dynamics of vehicle-structure interaction of beam traversed by a two-axle moving vehicle will be formulated.

\subsection{Non-Uniform Beam Traversed by a Concentrated Moving Mass}

A non-uniform cross-section beam subjected to a moving concentrated mass is shown in Fig. 1.

When the finite element method was used to solve this class of problems, the structures were modeled as an assemblage of beam elements and the governing equations, neglecting the rotary inertia and shearing force effects, were written as:

$$
[M]\{\ddot{d}\}+[C]\{\dot{d}\}+[K]\{d\}=\{F(t)\}=\left\{N^{t}\right\} f_{0} .
$$

In the above equation, $[M],[C],[K],\{d\}$, and $\{F(t)\}$ are the structural mass, damping and stiffness matrices, vector of structural nodal displacements, and load vector respectively.
Cubic Hermitian polynomials ${ }^{25}$ were used as the interpolation functions for the finite element formulation. In Eq. (1), $\left\{N^{t}\right\}$ was a vector with zero entries, except those corresponding to the nodal displacement of the element in which the load was positioned. These non-zero entries were the shape functions evaluated at the point where the load was acting.

The force $f_{0}$, including the gravitational and inertial forces of mass acting on the loaded element, were given as:

$$
f_{0}=M_{p} g-M_{p} \ddot{y}(x, t) .
$$

If there was no loss of contact between the mass and the upper surface of the beam, the respective expressions for the vertical displacement of the mass moving along a vibrating curvilinear path, can be written as:

$$
y(x, t)=w(x, t)+r(x) ;
$$

where $w(x, t)$ was the upward transversal dynamic deflection of the beam structure and $r(x)$ was the surface roughness of the beam, which referred to the road waviness and was represented as the vertically upward departure from the mean horizontal profile.

The function $w(x, t)$ was interpolated from the nodal displacements as $w=[N]\{d\}$, where $[N]$ was the matrix of interpolation functions. Assuming the upper surface of the beam was flat, then:

$$
\begin{aligned}
& y(x, t)=w(x, t) ; \\
& \dot{y}(x, t)=\dot{w}(x, t) ; \\
& \ddot{y}(x, t)=\ddot{w}(x, t) ;
\end{aligned}
$$

and the time derivatives of $w(x, t)$ were given by:

$$
\begin{aligned}
& \dot{w}(x, t)=\frac{\partial w}{\partial x} \dot{x}+\frac{\partial w}{\partial t} \\
& \ddot{w}(x, t)=\frac{\partial^{2} w}{\partial t^{2}}+2 \frac{\partial^{2} w}{\partial x \partial t} \dot{x}+\frac{\partial^{2} w}{\partial x^{2}} \dot{x}^{2}+\frac{\partial w}{\partial x} \ddot{x} .
\end{aligned}
$$

The first term on the right-hand of Eq. (6) was the support beam acceleration at the point of contact with the moving load and the second term denoted the well-known Coriolis acceleration since the load was moving along a vibrating curvilinear path (i.e., the support beam). The third term on Eq. (6) was the centripetal acceleration of the moving load and the fourth term indicated the acceleration component in the vertical direction when the moving load speed was not assumed as constant.

Using the nodal displacements interpolations and noting that $[N]$ contains only a spatial variable and $\{d\}$ is time dependent yielded: ${ }^{19}$

$$
\begin{aligned}
\frac{\partial^{2} w}{\partial x^{2}} & =[N]_{x x}\{d\} \\
\frac{\partial^{2} w}{\partial x \partial t} & =[N]_{x}\{\dot{d}\} \\
\frac{\partial w}{\partial x} & =[N]_{x}\{d\} \\
\frac{\partial^{2} w}{\partial t^{2}} & =[N]\{\ddot{d}\}
\end{aligned}
$$

where the subscript $x$ denoted the differentiation with respect to $x$. Assuming that the mass moving with a velocity of $\dot{x}$ and an acceleration of $\ddot{x}$, and substituting Eqs. (2) to (7) into Eq. (1), yielded:

$$
\left[M+M^{*}\right]\{\ddot{d}\}+\left[C+C^{*}\right]\{\dot{d}\}+\left[K+K^{*}\right]\{d\}=m g\left\{N^{t}\right\} ;
$$




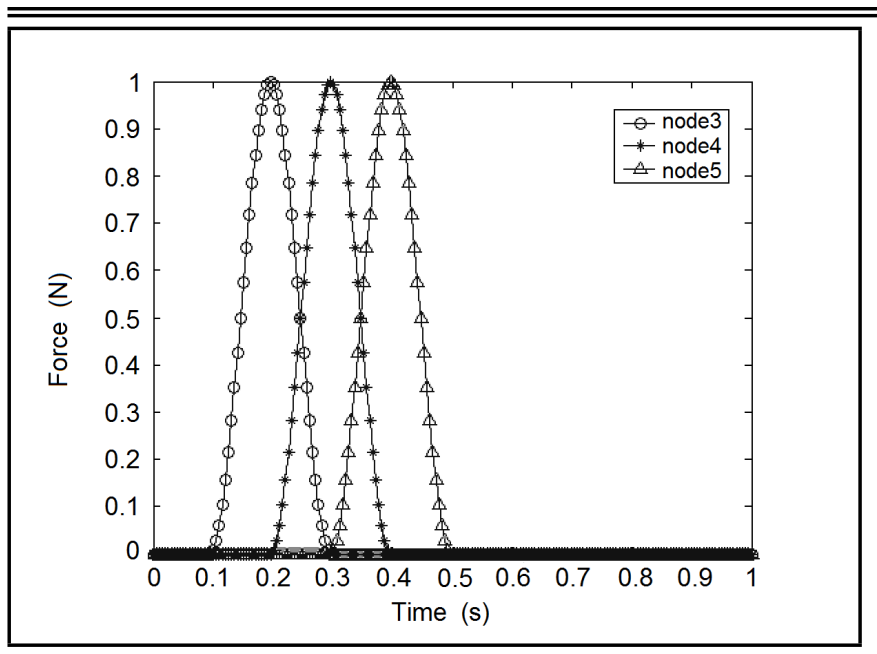

Figure 2. Time history of force in the nodes 3, 4, and 5 .

where

$$
\begin{aligned}
{\left[M^{*}\right] } & =m\left\{N^{t}\right\}[N] \\
{\left[C^{*}\right] } & =2 m \dot{x}\left\{N^{t}\right\}[N]_{x} ; \\
{\left[K^{*}\right] } & =m \dot{x}^{2}\left\{N^{t}\right\}[N]_{x x}+m \ddot{x}\left\{N^{t}\right\}[N] .
\end{aligned}
$$

The external force vector $m g\left\{N^{t}\right\}$ took the following form:

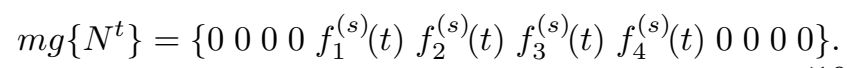

For a beam element with four degrees of freedom, the number of non-zero entries within the $n \times 1$ vector was four. Based on the load position along the beam, this $4 \times 1$ sub-vector was time dependent. On the other hand, as the load moved to another element, this sub-vector shifted to a position corresponding to the degrees of freedom of that element.

To illustrate the principles involved, consider a constant force travel with a constant velocity of $1 \mathrm{~m} / \mathrm{s}^{2}$ from one end to the other of a simply supported beam of $1 \mathrm{~m}$ length that was modeled by 10 beam elements. Figure 2 shows the force-time graph for three nodes of the beam in the time period when their values are non-zero.

The matrices $\left[M^{*}\right],\left[C^{*}\right]$, and $\left[K^{*}\right]$ have zero entries, except those corresponding to the element on which mass was acting upon. Thus, a non-zero $4 \times 4$ sub-matrix that was time dependent translated to the position corresponding to the degrees of freedom of the element, where the mass was acting that indicated the inertia effects of the moving load. The governing equations of problem were a system of second-order time dependent coefficients ordinary differential equations that were generally solved by using direct step-by-step integration methods.

\subsection{Non-Uniform Beam Traversed by a Simple Quarter-Car Model}

A wide span bridge that was modeled as a simply supported non-uniform beam was traversed by a moving vehicle in the form of a simple quarter-car (SQC) planar model, as shown in Fig. 3. The dynamic analysis of this problem was considerably more involved than for the one with a moving concentrated mass. The moving SQC model was considered as a dynamic system with two degrees of freedom (2-DOF) in which $M_{1}$ and $M_{2}$ were the unsprung mass and sprung mass of the moving vehicle respectively. The vertical displacements of the

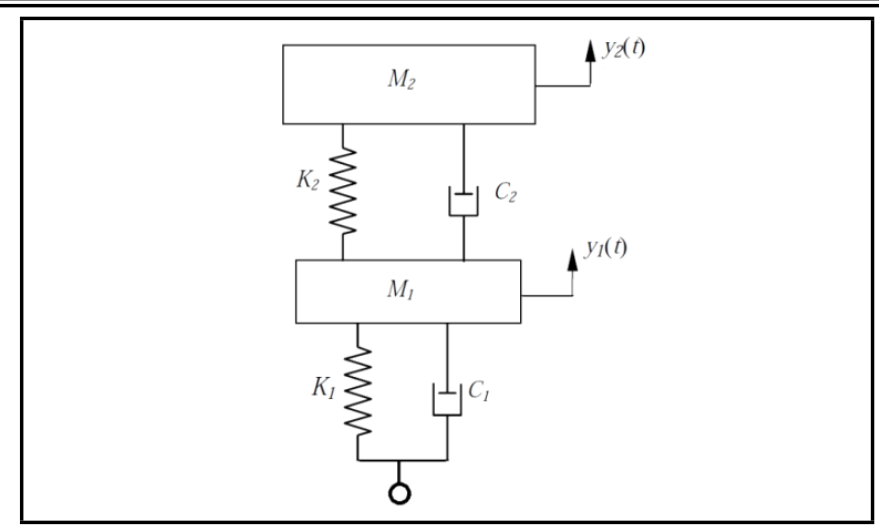

Figure 3. Moving simple quarter-car (SQC) model.

unsprung and sprung masses with reference to their respective vertical equilibrium positions were $y_{1}(t)$ and $y_{2}(t)$ respectively. The horizontal position of the center of the mass of the moving vehicle was measured from the left end of the beam.

The governing equations of the moving system and the beam can be obtained by using the finite element formulation as:

$$
\begin{aligned}
& M_{2} \ddot{y}_{2}+ C_{2}\left(\dot{y}_{2}-\dot{y}_{1}\right)+K_{2}\left(y_{2}-y_{1}\right)=0 \\
& M_{1} \ddot{y}_{2}+\left(C_{1}+C_{2}\right) \dot{y}_{1}-C_{1} \dot{w}-C_{2} \dot{y}_{2}+ \\
&\left(K_{1}+K_{2}\right) y_{1}-K_{1} w-K_{2} y_{2}=0 \\
& {[M]\{\ddot{d}\}+[C]\{\dot{d}\}+[K]\{d\}=\{F(t)\}=\left\{N^{t}\right\} F_{T} }
\end{aligned}
$$

where Eqs. (12) and (13) govern the vertical motion of $M_{1}$ and $M_{2}$ and $F_{T}$ was the vertical interaction force acting between the moving vehicle and beam. This interaction force could therefore be written from the free-body diagrams of the moving vehicle as: ${ }^{8}$

$$
\begin{aligned}
F_{T} & =C_{1}\left(\dot{w}-\dot{y}_{1}\right)+K_{1}\left(w-y_{1}\right) \\
& =M_{1} g+M_{1} \ddot{y}_{1}+C_{2}\left(\dot{y}_{1}-\dot{y}_{2}\right)+K_{2}\left(y_{1}-y_{2}\right) ;
\end{aligned}
$$

where $g$ was the acceleration due to gravity. It should be noted that the first expression in Eq. (14) was obtained by using force balance at the tire contact point with the road, while the second expression was rendered by using force balance at $M_{1}$. The interaction force $F_{T}$ could also be described as:

$$
F_{T}=\left(M_{1}+M_{2}\right) g-M_{1} \ddot{y}_{1}-M_{2} \ddot{y}_{2} \text {. }
$$

The present derivation was based on the fact that the transmitted force could be described by using the external excitation force and the inertia of the dynamic system rather than spring and forces.

From Eqs. (5), (6), and (14), it could be seen that the interaction force $F_{T}$ between the moving vehicle and the beam depended on the velocity and acceleration of the vehicle and the flexibility of the beam structure. The interaction force did indeed vary with time, which could be taken as an indicator of separation. When this force became zero, it denoted the onset of separation, and it should remain zero until the moving vehicle made contact with the beam surface.

Using Eqs. (4) and (5) and substituting them into Eqs. (11) 


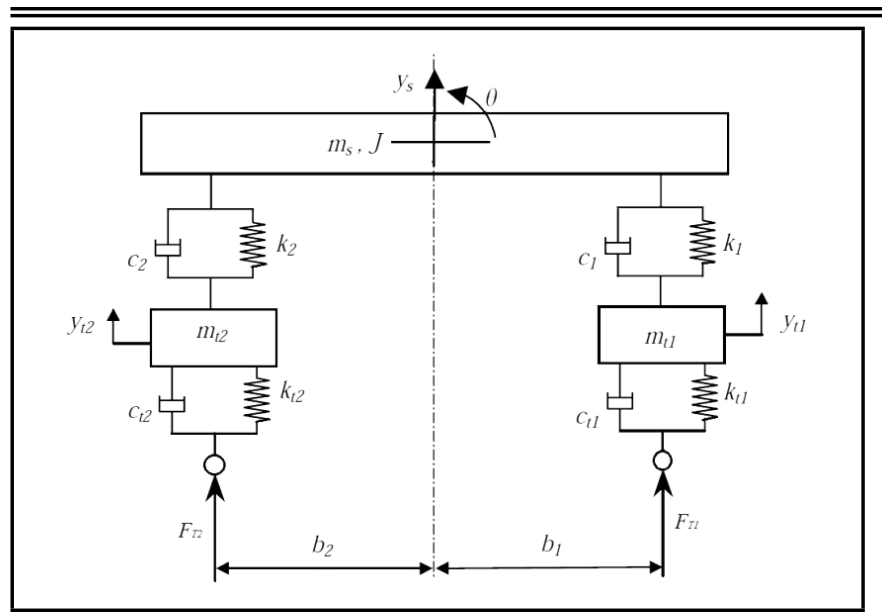

Figure 4. Moving planar 4 DOF half-car model.

to (14), the governing equations of this case were obtained as:

$$
\begin{gathered}
\left(\begin{array}{ccc}
{[M]} & \left\{N^{t}\right\} M_{1} & \left\{N^{t}\right\} M_{2} \\
{[0]} & M_{1} & 0 \\
{[0]} & 0 & M_{2}
\end{array}\right)\left(\begin{array}{c}
\{\ddot{d}\} \\
\ddot{y}_{1} \\
\ddot{y}_{2}
\end{array}\right)+ \\
\left(\begin{array}{ccc}
{[C]} & 0 & 0 \\
-C_{1}[N] & C_{1}+C_{2} & -C_{2} \\
{[0]} & -C_{2} & C_{2}
\end{array}\right)\left(\begin{array}{c}
\{\dot{d}\} \\
\dot{y}_{1} \\
\dot{y}_{2}
\end{array}\right)+ \\
\left(\begin{array}{ccc}
{[K]} & 0 & 0 \\
-C_{1} \dot{x}[N]_{x}+K_{1}[N] & K_{1}+K_{2} & -K_{2} \\
{[0]} & -K_{2} & K_{2}
\end{array}\right)\left(\begin{array}{c}
\{d\} \\
y_{1} \\
y_{2}
\end{array}\right)=
\end{gathered}
$$

\subsection{Non-Uniform Beam Traversed by a Two-Axle Moving Dynamic System}

The moving vehicle, assumed as a two-axle dynamic system with four DOF, is illustrated in Fig. 4. The vehicle model consists of a sprung mass (body) and two unsprung masses (axles). The body was considered to have the vertical motion (bounce) and the angular motion (pitch), with every axle having its own vertical motion. It was assumed that the vehicle advanced along the beam with the specified velocity $\dot{x}(t)$ where $x(t)$ was the position of the center of gravity (c.g.) of the vehicle, as shown in Fig. 4. Moreover, at $t=0$, the front axle of the vehicle initially entered the beam from the left-end support. In this case, such as for previous moving loads, the contact between vehicle tire and beam were checked via interaction force.

In order to generate the governing equations of motion for the moving dynamic system and the beam interaction model, the energy method could be applied. ${ }^{9}$ The equation of vertical motion for the sprung mass was:

$$
\begin{aligned}
m_{s} \ddot{y}_{s}+ & c_{1}\left(\dot{y}_{s}+b_{1} \dot{\theta}-\dot{y}_{t 1}\right)+c_{2}\left(\dot{y}_{s}-b_{2} \dot{\theta}-\dot{y}_{t 2}\right)+ \\
& k_{1}\left(y_{s}+b_{1} \theta-y_{t 1}\right)+k_{2}\left(y_{s}-b_{2} \theta-y_{t 2}\right)=0 .
\end{aligned}
$$

The equation of the angular motion (pitch) of the sprung mass had the following form:

$$
\begin{array}{r}
J \ddot{\theta}+c_{1} b_{1}\left(\dot{y}_{s}+b_{1} \dot{\theta}-\dot{y}_{t 1}\right)-c_{2} b_{2}\left(\dot{y}_{s}-b_{2} \dot{\theta}-\dot{y}_{t 2}\right)+ \\
k_{1} b_{1}\left(y_{s}+b_{1} \theta-y_{t 1}\right)-k_{2} b_{2}\left(y_{s}-b_{2} \theta-y_{t 2}\right)=0 .
\end{array}
$$

The equation of the vertical motion (bounce) for the front axle was:

$$
\begin{aligned}
m_{t 1} \ddot{y}_{t 1}+ & c_{1}\left(\dot{y}_{t 1}-\dot{y}_{s}-b_{1} \dot{\theta}\right)+c_{t 1}\left(\dot{y}_{t 1}-\dot{w}_{1}\right)+ \\
& k_{1}\left(y_{t 1}-y_{s}-b_{1} \theta\right)+k_{t 1}\left(y_{t 1}-w_{1}\right)=0 .
\end{aligned}
$$

The vertical motion (bounce) of the rear axle was governed by:

$$
\begin{aligned}
m_{t 2} \ddot{y}_{t 2}+ & c_{2}\left(\dot{y}_{t 2}-\dot{y}_{s}+b_{2} \dot{\theta}\right)+c_{t 2}\left(\dot{y}_{t 2}-\dot{w}_{2}\right)+ \\
& k_{2}\left(y_{t 2}-y_{s}+b_{2} \theta\right)+k_{t 2}\left(y_{t 2}-w_{2}\right)=0 .
\end{aligned}
$$

For the finite element formulation in this case, since there were two contact points acting on the beam element, the dynamic interaction forces between the beam and the moving system were calculated with the shape functions evaluated at the locations corresponding to the respective axle positions. Considering the approach used for the previous case for each moving axle, the governing finite element equations of the beam were subjected to a moving two-axle vehicle obtained as:

$$
\begin{aligned}
{[M]\{\ddot{d}\}+[C]\{\dot{d}\}+[K]\{d\} } & =\{F(t)\} \\
& =\left\{N^{t}\right\}_{1} F_{T 1}+\left\{N^{t}\right\}_{2} F_{T 2}
\end{aligned}
$$

where

$$
\begin{aligned}
& F_{T 1}=\left[\frac{b_{2}}{b_{1}+b_{2}}\left(m_{s} g-m_{s} \ddot{y}_{s}-\frac{J}{b_{2}} \ddot{\theta}\right)+m_{t 1} g-m_{t 1} \ddot{y}_{t 1}\right] ; \\
& F_{T 2}=\left[\frac{b_{1}}{b_{1}+b_{2}}\left(m_{s} g-m_{s} \ddot{y}_{s}-\frac{J}{b_{1}} \ddot{\theta}\right)+m_{t 2} g-m_{t 2} \ddot{y}_{t 2}\right] ;
\end{aligned}
$$

and $\left\{N^{t}\right\}_{1}$ and $\left\{N^{t}\right\}_{2}$ denoted the shape functions evaluated at points $x_{1}$ and $x_{2}$, which corresponded to the positions of the front and rear axles of the moving vehicle respectively. Therefore, the governing equations of the moving system and beam could be derived as Eq. (24) (see next page), where

$$
\begin{aligned}
f_{y 1} & =\frac{b_{2}}{b_{1}+b_{2}} m_{s} ; & f_{\theta 1} & =\frac{J}{b_{1}+b_{2}} \\
f_{y 2} & =\frac{b_{1}}{b_{1}+b_{2}} m_{s} ; & f_{\theta 2} & =\frac{-J}{b_{1}+b_{2}} .
\end{aligned}
$$

The governing equations developed here were applicable to a wide range of general moving load problems. It could be used for beams with various boundary conditions. Damping in both the moving vehicle and the support beam could be treated using the present technique. The compliances of the suspension system and the tires were modeled by a combination of linear springs and viscous dampers connected in parallel arrangements. Furthermore, the Rayleigh damping of the form $[C]=\alpha[M]+\beta[K]$, was used for the beam to examine its effect on the structural response. Knowing the modal damping ratios for the first two modes, the coefficients $\alpha$ and $\beta$ could be determined as: ${ }^{26}$

$$
\alpha=\frac{2 \omega_{1} \omega_{2}\left(\zeta_{1} \omega_{2}-\zeta_{2} \omega_{1}\right)}{\left(\omega_{2}^{2}-\omega_{1}^{2}\right)} ; \quad \beta=\frac{2\left(\zeta_{2} \omega_{2}-\zeta_{1} \omega_{1}\right)}{\left(\omega_{2}^{2}-\omega_{1}^{2}\right)}
$$

\subsection{Longitudinal Stress}

The nodal deflections and slopes may be used to obtain the elements resultant. In this case, the internal moments $M_{b}$ and 


$$
\begin{aligned}
& \left(\begin{array}{ccccc}
{[M]} & \sum_{i=1}^{2}\left\{N^{t}\right\}_{i} f_{y i} & \sum_{i=1}^{2}\left\{N^{t}\right\}_{i} f_{\theta i} & \left\{N^{t}\right\}_{1} m_{t 1} & \left\{N^{t}\right\}_{2} m_{t 2} \\
{[0]} & m_{s} & 0 & 0 & 0 \\
0 & 0 & J & 0 & 0 \\
{[0]} & 0 & 0 & m_{t 1} & 0 \\
{[0]} & 0 & 0 & 0 & m_{t 2}
\end{array}\right)\left(\begin{array}{c}
\{\ddot{d}\} \\
\ddot{y}_{s} \\
\ddot{\theta} \\
\ddot{y_{t 1}} \\
\ddot{y}_{t 2}
\end{array}\right)+ \\
& \left(\begin{array}{ccccc}
{[C]} & 0 & 0 & 0 & 0 \\
{[0]} & \sum_{i=1}^{2} c_{i} & \sum_{i=1}^{2}(-1)^{i+1} c_{i} b_{i} & -c_{1} & -c_{2} \\
{[0]} & \sum_{i=1}^{2}(-1)^{i+1} c_{i} b_{i} & \sum_{i=1}^{2} c_{i} b_{i}^{2} & -c_{1} b_{1} & c_{2} b_{2} \\
\{N\}_{1} c_{t 1} & -c_{1} & -c_{1} b_{1} & c_{1}+c_{t 1} & 0 \\
\{N\}_{2} c_{t 2} & -c_{2} & c_{2} b_{2} & 0 & c_{2}+c_{t 2}
\end{array}\right)\left(\begin{array}{c}
\{\dot{d}\} \\
\dot{y}_{s} \\
\dot{\theta} \\
\dot{\dot{y}_{t 1}} \\
\dot{y}_{t 2}
\end{array}\right)+ \\
& \left(\begin{array}{ccccc}
{[K]} & 0 & 0 & 0 & 0 \\
{[0]} & \sum_{i=1}^{2} k_{i} & \sum_{i=1}^{2}(-1)^{i+1} k_{i} b_{i} & -k_{1} & -k_{2} \\
{[0]} & \sum_{i=1}^{2}(-1)^{i+1} k_{i} b_{i} & \sum_{i=1}^{2} k_{i} b_{i}^{2} & -k_{1} b_{1} & k_{2} b_{2} \\
c_{t 1}[N]_{x 1} \dot{x}_{1}-k_{t 1}[N]_{1} & -k_{1} & -k_{1} b_{1} & k_{1}+k_{t 1} & 0 \\
c_{t 2}[N]_{x 2} \dot{x}_{2}-k_{t 2}[N]_{2} & -k_{2} & -k_{2} b_{2} & 0 & k_{2}+k_{t 2}
\end{array}\right)\left(\begin{array}{c}
\{d\} \\
y_{s} \\
\theta \\
y_{t 1} \\
y_{t 2}
\end{array}\right)=\left(\begin{array}{c}
\sum_{i=1}^{2}\left\{N^{t}\right\}_{i}\left(f_{y i}+m_{t i}\right) g \\
0 \\
0 \\
0 \\
0
\end{array}\right) ;
\end{aligned}
$$

maximum longitudinal stresses $\sigma_{\max }$ along the beam may be evaluated as: $:^{27}$

$$
\begin{aligned}
M_{b} & =\frac{E I}{L^{2}} \frac{d^{2}[N]}{d \zeta^{2}}\{d\}^{e} ; \\
\sigma_{\max } & =\frac{M_{b} h}{I} .
\end{aligned}
$$

$c$ was the distance from the natural plane to the outermost fiber of the beam and $I$ was the second moment of area. In the case of a non-uniform cross-section beam, we used an average value of $I$ and $c$ for each element. Therefore, the results did not have the absolutely exact value, but these were appropriate for comparison of stress distribution along the beams with different thickness profile.

\subsection{Modeling the Non-Uniformity of a Cross-Section}

For modeling the non-uniformity of a cross-section of the beam, we must refer to the derivation of structural mass and stiffness matrices. Using the interpolation function explained before, the structural mass and stiffness matrices of element $j$ could be written as: ${ }^{26}$

$$
\begin{aligned}
k_{j} & =\frac{1}{l^{3}} \int_{0}^{1} E I_{j}(\zeta) \frac{d^{2}[N]}{d \zeta^{2}} \frac{d^{2}[N]^{T}}{d \zeta^{2}} d \zeta \\
m_{j} & =l \int_{0}^{1} \mu_{j}(\zeta)[N][N]^{T} d \zeta
\end{aligned}
$$

where $\zeta$ represented the local coordinate, $E, I_{j}(\zeta), \mu_{j}(\zeta)$, and $l$ are the Young modulus, second moment of area along the element, mass per unit length of the element, and length of element respectively.

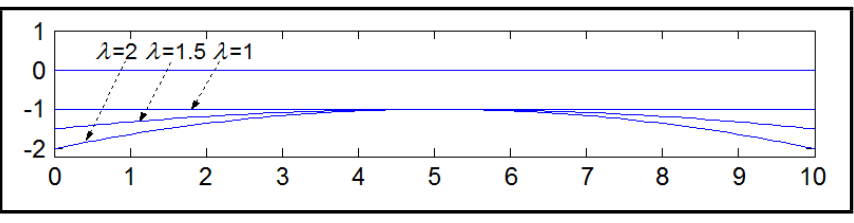

Figure 5. Variation of thickness along the beam length.

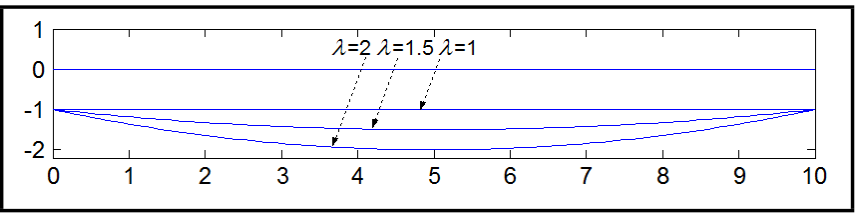

Figure 6. Variation of thickness along the beam length.

For the case of a uniform cross-section beam, $E I_{j}$ and $\mu_{j}$ were constant over the element, but for the case of a nonuniform cross-section, $E I_{j}(\zeta)$ and $\mu_{j}(\zeta)$ were variable over the element, and the integration was carried out on them. For instance, the beam of constant width and parabolically varying thickness illustrated in Fig. 5. Its thickness was given by the following equation: ${ }^{14}$

$$
h(x)=h_{b} f(x)=h_{b}\left[4(\gamma-1)\left(\frac{x^{2}}{L^{2}}-\frac{x}{L}\right)+\gamma\right]
$$

where

$$
\gamma=\frac{h_{m}}{h_{b}}
$$

and $h_{b}$ and $h_{m}$ were the minimum and maximum thickness of the beam.

Consequently, the cross-section area, second moment of area, and mass per unit length of the beam was:

$$
A(x)=A_{b} f(x) ; \quad I(x)=I_{b} f(x) ; \quad \mu(x)=\rho A(x) ;
$$




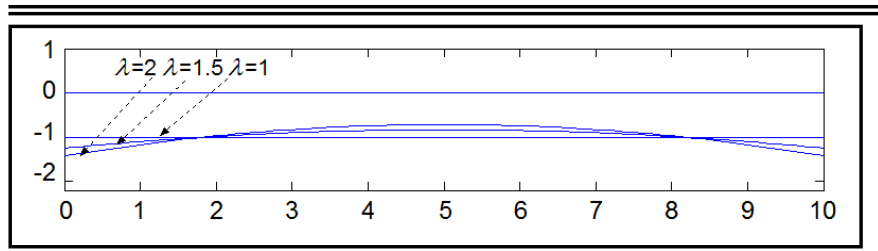

Figure 7. Variation of thickness of beam with constant weight based on Eq. (36).

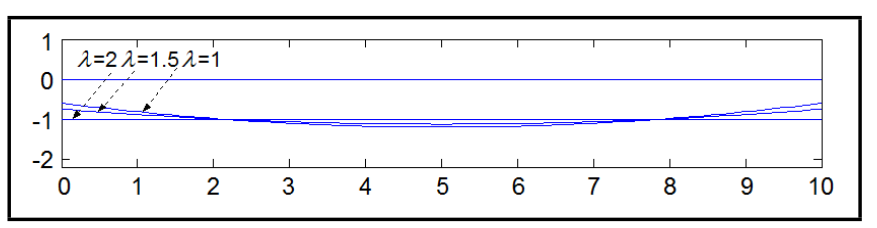

Figure 8. Variation of thickness of beam with constant weight based on Eq. (37).

where $A_{b}$ and $I_{b}$ were the cross-section area and second moment of area of uniform beam. And $\rho$ was the density of beam.

Since the characteristics of the beam were variable over the length of the beam and also over the beam element, the variation of thickness of beam was implemented in the structural mass and stiffness matrices. The thickness profile of the beam could be any analytical function of length. As a different example, the thickness could be as follows:

$$
h(x)=h_{b} f(x)=h_{b}\left[\gamma+1-4(\gamma-1)\left(\frac{x^{2}}{L^{2}}-\frac{x}{L}\right)+\gamma\right]
$$

it is illustrated in Fig. 6.

In order to have same weight in beams with a different maximum to minimum thickness ratio ( $\gamma$ parameter), we used different minimum thicknesses which were obtained from following equations for Eqs. (31) and (33) respectively:

$$
\begin{aligned}
h_{b \gamma} & =\frac{3 h_{b}}{2+\gamma} ; \\
h_{b \gamma} & =\frac{3 h_{b}}{1+2 \gamma} .
\end{aligned}
$$

The new form of these equations was:

$$
\begin{array}{r}
h(x)=h_{b \gamma} f(x)=h_{b \gamma}\left[4(\gamma-1)\left(\frac{x^{2}}{L^{2}}-\frac{x}{L}\right)+\gamma\right] \\
h(x)=h_{b \gamma} f(x)=h_{b \gamma}\left[\gamma+1-4(\gamma-1)\left(\frac{x^{2}}{L^{2}}-\frac{x}{L}\right)+\gamma\right] .
\end{array}
$$

Figures 7 and 8 illustrate the variation of thickness for beam of constant weight.

\section{THE SOLUTION METHOD}

Now we can solve the governing equations in each case by knowing the $[M],[K],[C],\left[M^{*}\right],\left[C^{*}\right],\left[K^{*}\right]$, and $\left\{N^{t}\right\}$ by applying the Wilson- $\theta$ method implicitly. The Wilson- $\theta$ method is basically a linear acceleration method that a linear change of acceleration is assumed from time $t$ to $t+\Delta t$. Assuming that $\tau$ indicates the time and $0 \leq \tau \leq \theta \Delta t$, then for this time interval, we may write: ${ }^{25}$

$$
{ }^{t+\tau} \ddot{U}=\ddot{U}+\frac{\tau}{\theta \Delta t}\left({ }^{t+\theta \Delta t} \ddot{U}-{ }^{t} \ddot{U}\right) .
$$

Table 1. Impact factor for the central displacement of a simply supported beam under moving force.

\begin{tabular}{|c|c|c|c|}
\hline$T_{f} / T$ & Exact $^{28}$ & Present study & Lin $^{13}$ \\
\hline 0.1 & 1.050 & 1.048 & 1.053 \\
0.5 & 1.250 & 1.251 & 1.252 \\
1.0 & 1.707 & 1.705 & 1.705 \\
1.234 & 1.743 & 1.732 & 1.730 \\
1.5 & 1.710 & 1.708 & 1.704 \\
2.0 & 1.550 & 1.549 & 1.550 \\
\hline
\end{tabular}

The parameter $\theta$ is a constant that must be $\theta \geq 1.37$ in order to have unconditional stability. The value $\theta=1.4$ was used in this case. For calculating acceleration, velocity, and displacement in time $t+\Delta t$, the equilibrium equation, was considered in time $t+\theta \Delta t$. A load vector could be extrapolated linearly using assumed linear acceleration change. So, the following equation was used:

$$
M^{t+\theta \Delta t} \ddot{U}+C^{t+\theta \Delta t} \dot{U}+K{ }^{t+\theta \Delta t} U={ }^{t+\theta \Delta t} R
$$

where

$$
{ }^{t+\theta \Delta t} R={ }^{t} R+\theta\left({ }^{t+\Delta t} R-{ }^{t} R\right) .
$$

To solve the related equation, a computer program was developed based on the mentioned numerical technique. Furthermore, in order to ensure the stability and convergence of the solution, sufficiently small time steps were used. Based on our results, the present method converged to the solution efficiently.

\section{IMPLEMENTATION AND VALIDATION}

To check the present technique, some classical and wellknown problems of moving concentrated force and mass problem are presented and compared with the exact analytical solution and published papers.

\subsection{Simply Supported Beam Subjected to a Moving Concentrated Force}

A uniform un-damped simply supported beam of length $L=47 \mathrm{in}$ and the cross-section area of $A=7.90625 \mathrm{in}^{2}$ was modeled with 20 beam elements. The beam had a density of $\rho=2.770 \times 10^{-4} \mathrm{lbs}^{2} / \mathrm{in}^{4}$, a modulus of elasticity $E=15.2 \times 10^{6} \mathrm{psi}$, and a second moment of area $I=22.7 \mathrm{in}^{4}$. A concentrated force started at the left end and traveled to the right end with a constant velocity. Figure 9 illustrates the ratio of dynamic to static deflection (impact factor) of the center of the beam for a different moving force velocity. $T_{f} / T$ represents the ratio of the period of the first natural vibration of the beam to a traveling time of a moving force on the beam.

Results of a similar numerical and analytical analysis by $\operatorname{Lin}^{13}$ and Warburton ${ }^{28}$ respectively along with the present study are summarized in Table 1. It was observed that there was a good agreement between them.

\subsection{Simply Supported Beam Subjected to a Moving Mass}

Consider a simply supported beam under a point mass including a moving mass inertia while shear deformation and rotary inertia of the beam were neglected. The parameters of the problem are: $L=4.352 \mathrm{~m}, E=2.02 e^{11} \mathrm{~N} / \mathrm{m}^{2}$, $I=5.17 e^{-7} \mathrm{~m}^{4}, \rho=15267 \mathrm{~kg} / \mathrm{m}^{3}, A=1.31 e^{-3} \mathrm{~m}^{2}$, moving mass $M_{p}=21.8 \mathrm{~kg}$, gravitational acceleration $g=$ $9.806 \mathrm{~m} / \mathrm{s}^{2}$, and speed of moving mass $V=27.49 \mathrm{~m} / \mathrm{s}$. In 


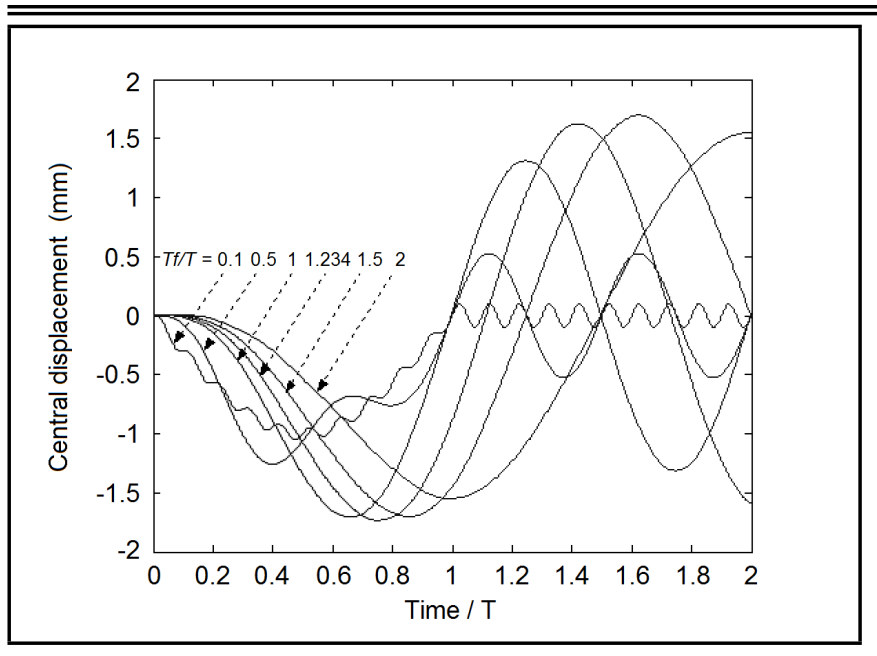

Figure 9. Central displacement of a simply supported beam under moving force.

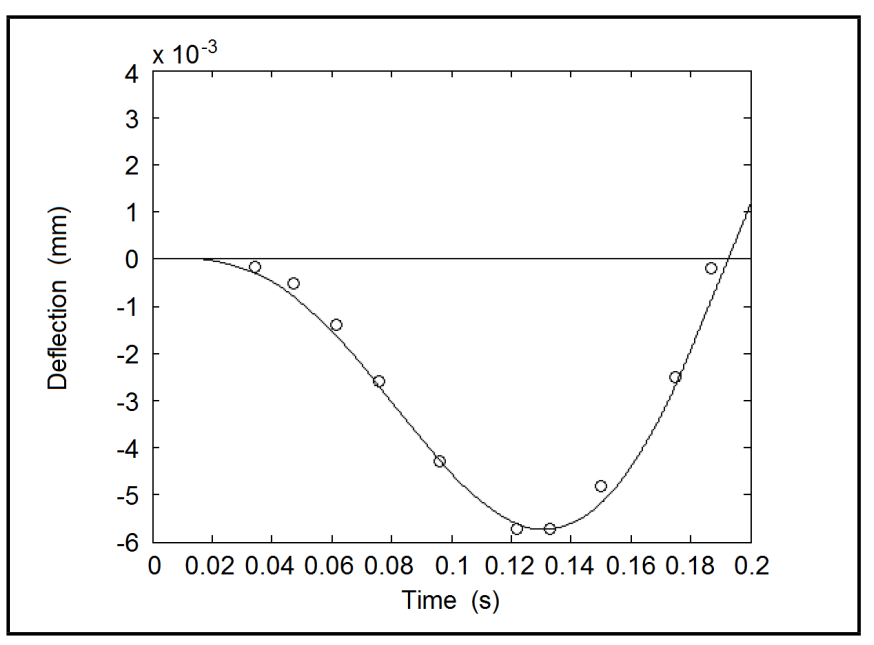

Figure 10. Time history diagram of the deflection of the mid-span, - , present method, o, finite difference method. ${ }^{7}$

the present case, the beam was modeled by 40 elements and the time history diagram of the deflection of the mid-span are demonstrated in Fig. 10 by a solid line. Comparing the results with those in the literature ${ }^{14}$ indicates very good agreement between the findings.

\subsection{Response Of A Cantilever Beam Subjected to a Moving Mass}

The cantilever beam with a moving mass and parameters of $M=3 \mathrm{lbs}^{2} / \mathrm{in}, V=2000 \mathrm{in} / \mathrm{s}, M_{p} / M=1.5, L=300 \mathrm{in}$, and $E I=6.81 \times 10^{9} \mathrm{lbin}^{2}$ was analyzed by an anaticalnumerical method ${ }^{13}$ and determined the dynamic behavior of the beam. This beam was modeled by 40 beam elements and a 0.001 time step was used to solve the problem by the Wilson- $\theta$ method. Figure 11 illustrates a deflection of the beam's end point and was obtained by two methods.

\section{NUMERICAL RESULTS AND DISCUSSION}

The behavior of a non-uniform cross-section beam carrying a moving load under different boundary conditions and vehicle body vibration, was analyzed. Using the parameter values: (1) Beam: $E=2.02 e^{11} \mathrm{~N} / \mathrm{m}^{2}, \rho=7800 \mathrm{~kg} / \mathrm{m}^{3}, L=10 \mathrm{~m}$, $I=0.15 \mathrm{~m}^{4}, c=1700 \mathrm{Ns} / \mathrm{m}$; (2) Vehicle: $m_{s}=1700 \mathrm{~kg}$, $m_{t 1}=80 \mathrm{~kg}, m_{t 2}=130 \mathrm{~kg}, J=3442.3 \mathrm{kgm}^{2}, b_{1}=1.2 \mathrm{~m}$,

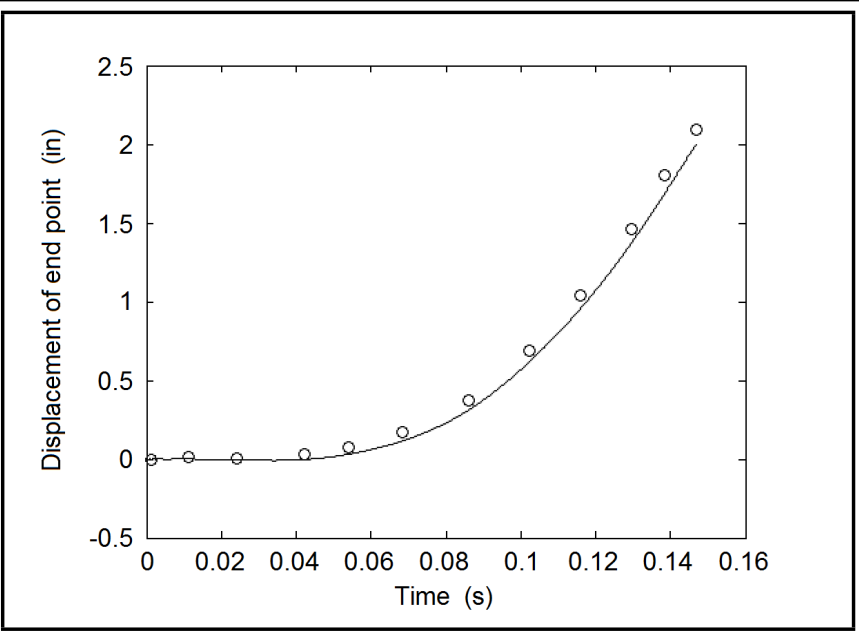

Figure 11. Time history diagram of the deflection of the end point of the beam, - , present method, o, analytical-numerical method. ${ }^{6}$

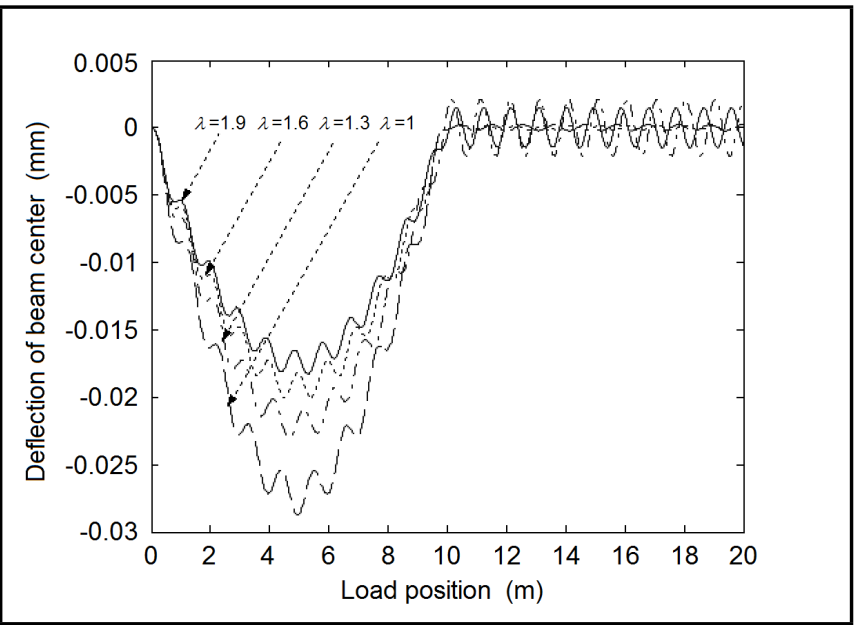

Figure 12. Central displacement of a simply supported non-uniform crosssection beam under moving mass without inertia effect.

$b_{2}=1.6 \mathrm{~m}, d_{1}=0.42 \mathrm{~m}, d_{2}=1.15 \mathrm{~m}, k_{1}=66800 \mathrm{~N} / \mathrm{m}$, $k_{2}=18600 \mathrm{~N} / \mathrm{m}, k_{t 1}=k_{t 2}=110000 \mathrm{~N} / \mathrm{m}, c_{1}=1100 \mathrm{Ns} / \mathrm{m}$, $c_{2}=1000 \mathrm{Ns} / \mathrm{m}, c_{t 1}=c_{t 2}=14 \mathrm{Ns} / \mathrm{m}$; and with a variable cross-section, the deflection, natural frequency, and longitudinal stress along the beam have been calculated.

Dynamic responses of the beam under moving mass with and without mass inertia effect for simply supported boundary conditions are illustrated in Figs. 12 and 13. It can be observed in these figures that increasing the ratio of maximum to minimum thickness of beam $(\gamma)$ for thickness profile of Eq. (37) keeping the total mass of the beam constant, the mid-span deflection of beam would decrease considerably.

By increasing $\gamma$ from 1 (uniform cross-section) to 1.9, the mid-span deflection decreased about $30 \%$ for the simply supported beam. The variation of maximum deflection of beam with respect to $\gamma$ for some constant velocities is illustrated in Fig. 14. Also as a result of increasing $\gamma$, the natural frequencies of beam increased. The variation of the first natural frequency for the simply supported boundary condition is illustrated in Fig. 15. It should be noted that in this analysis, the total mass of the beam was kept constant.

Changing the simply supported boundary conditions of the beam to clamped, the results are obtained as Fig. 16. In this case, the thickness profile was assumed to be that of Eq. (36). This profile was shown to be less effective for the clamped 


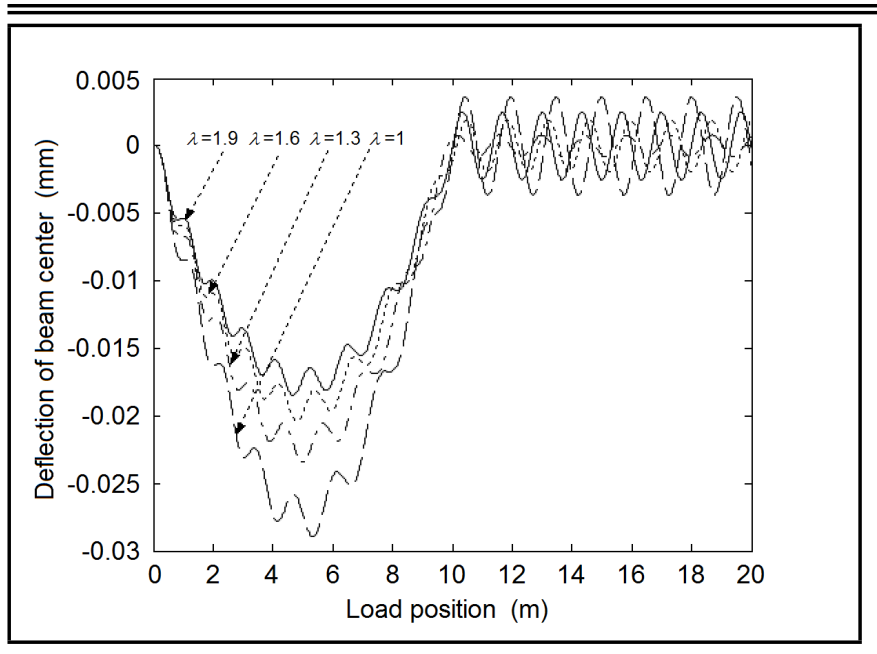

Figure 13. Central displacement of a simply supported non-uniform crosssection beam under moving mass including inertia effect.

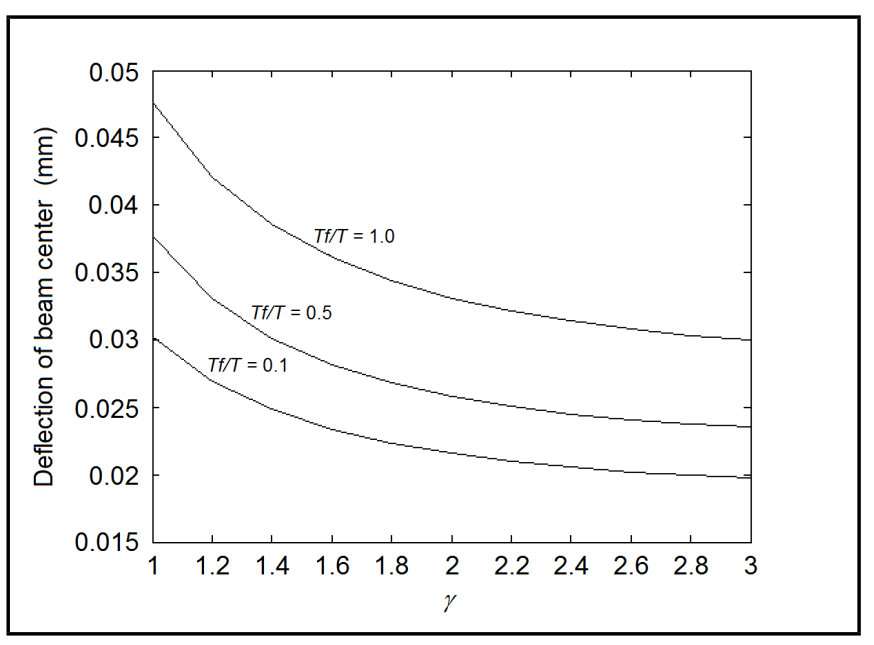

Figure 14. Maximum central deflection of simply supported beam under moving mass versus variation of thickness.

beam deflection than that of the simply supported beam. Improvement in this case was about $7 \%$.

The effect of $\gamma$ parameter on deflection of mid-span of the beam at various speeds of the load is illustrated in Fig. 17. It was clear that there existed a point, approximately $\gamma=1.8$, at which the deflection of the beam would be minimized. The variation of first natural frequency for clamped boundary conditions can also be seen in Fig. 18.

In order to observe the effect of mass velocity and inertia effect, the maximum deflection of the beam with and without the mass inertia effect versus the ratio of the period of the first natural vibration of the beam to the traveling time of the moving force on the beam (indicating velocity), was plotted in Figs. 19 and 20 for simply supported and clamped boundary conditions. It was clear that the difference between the maximum deflection of the beam for cases of moving force and moving mass was considerable at high speeds. The maximum deflection of the beam was achieved when the ratio of traveling time of load to the first natural period of the beam was about 1.23. The velocity of the force in this case was called critical velocity. A similar effect could be observed for the mass velocity. In this case, the critical speed depended on the ratio of the moving mass to the beam mass.

The transient response of the bounce motion of the vehicle body versus the vehicle position on the beam for different

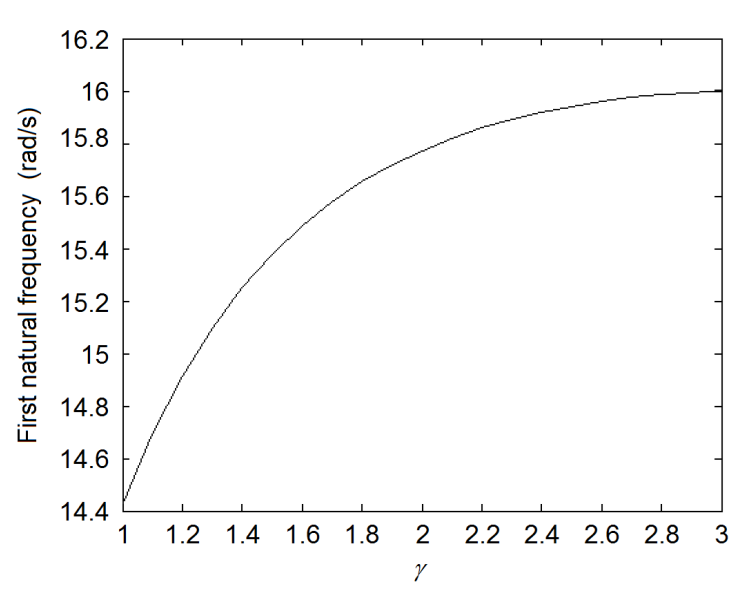

Figure 15. Minimum frequency of simply supported beam under moving mass versus variation of thickness.

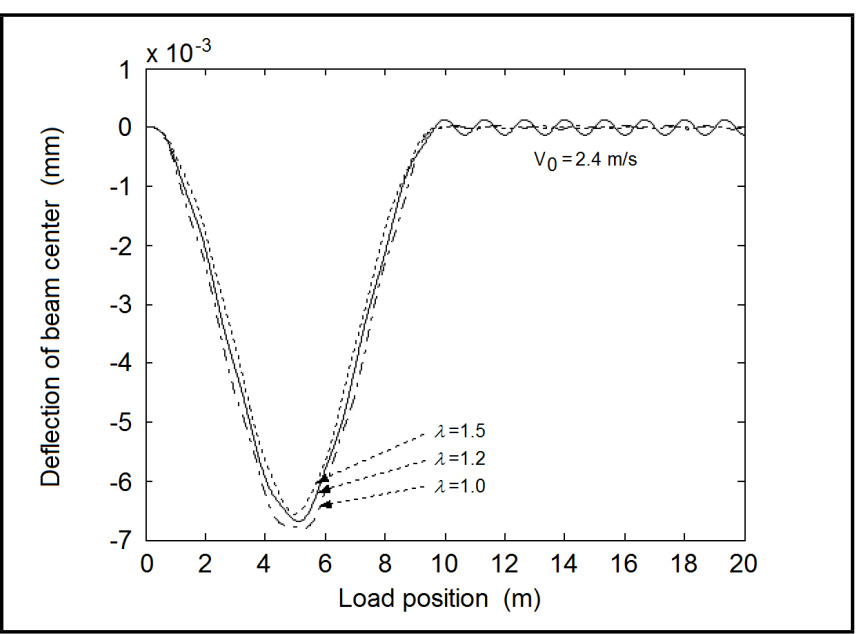

Figure 16. Central displacement of clamped non-uniform cross-section beam under moving mass.

values of the vehicle speed using half-car model is shown in Fig. 21.

It was clear that as the speed of vehicle varied, the vibration generated at the beam and vehicle body were considerably affected. The same analysis could be done for the SQC model. In this case, the beam parameters were kept the same and equivalent values for both SQC and half-car models were used as follows: $M_{2}=m_{s}, M_{1}=m_{t 1}+m_{t 2}, K_{1}=k_{t 1}+k_{t 2}$, $K_{2}=k_{1}+k_{2}, C 1=c_{t 1}+c_{t 2}, C_{2}=c_{1}+c_{2}$. Results of SQC simulation are depicted in Fig. 22. It could be concluded that the use of the half-car model provides more useful data for both vehicle dynamics and beam characteristics compared with SQC model.

As load proceeds along the beam, a maximum longitudinal stress occurs depending on the position of the load and configuration of the beam cross-section ( $\gamma$ parameter). Figure 23 presents the maximum stress along the simply supported beam versus variation of a cross-section based on Eq. (37) for each pass of the force at different speed of the load. It was clear that as the $\gamma$ parameter increased, the maximum stress decreased, while for a specified $\gamma$, as velocity increased, the maximum stress also increased.

For some, specified $\gamma$ maximum longitudinal stress at each cross-section is shown along the simply supported beam in Fig. 24. It was clear that in a uniform beam, maximum stress 


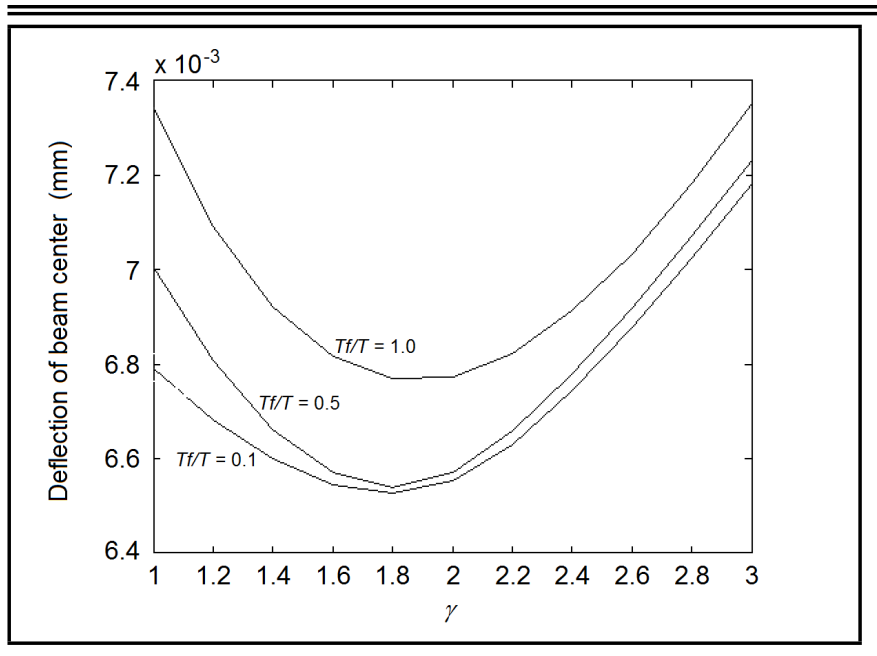

Figure 17. Maximum central deflection of simply supported beam under moving mass versus variation of thickness.

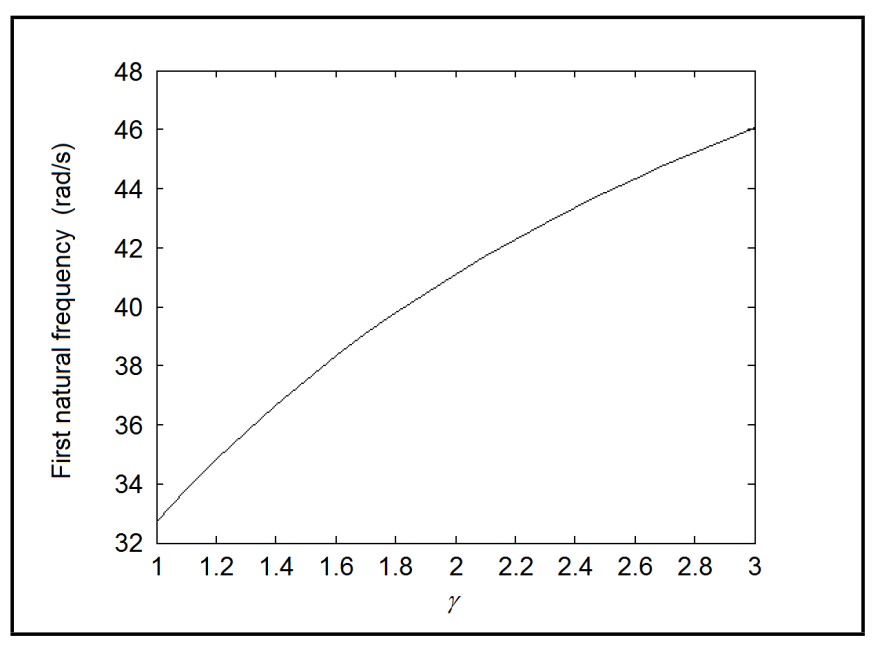

Figure 18. Minimum frequency of clamped beam versus variation of thickness.

occured around the mid-span of the beam. As $\gamma$ increased, the stress distribution from a quadratic form tended to be in a more uniform shape. This was true when the $\gamma$ parameter varied between 1 and 2.5; as $\gamma$ increased, a reverse situation could be seen.

The same investigation was conducted for a clamped beam using the thickness profile of Eq. (36). These results are illustrated in Figs. 25 and 26.

In order to present the time history of the bending longitudinal stress of each point along the beam, the waterfall depiction for a uniform and non-uniform cross-section beam are presented in Figs. 27 and 28 respectively. It was clear that the maximum stress was reduced considerably and higher uniformity was achieved in the non-uniform cross-section beam.

\section{CONCLUSIONS}

The problem of a non-uniform cross-section beam with different boundary conditions subjected to moving loads, such as a moving concentrated mass, a simple quarter-car (SQC) planar model, and a two-axle dynamic system with four DOF by developing the derivation of characteristic equations and including the effect of structural damping and moving load inertia on the beam, have been considered. Also, the dynamic deflection of the beam, critical speed of the moving vehicle, and distribution of maximum longitudinal stress along the beam is

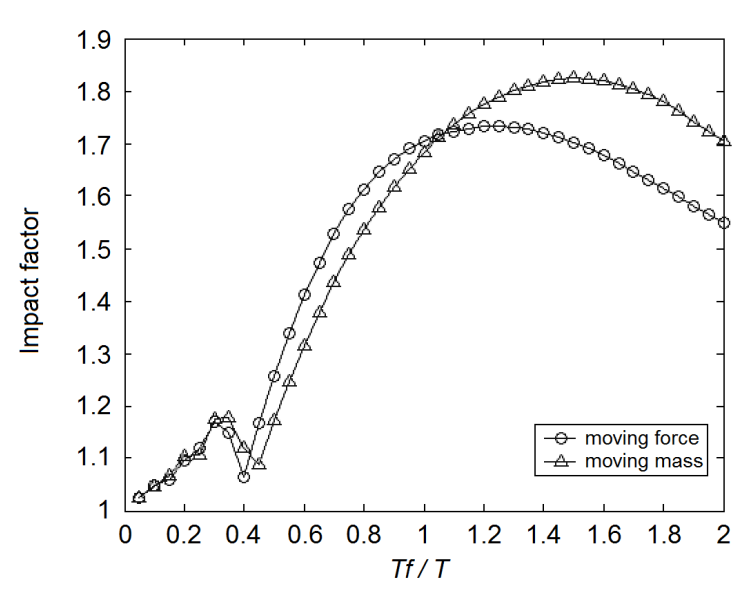

Figure 19. Impact factor for the central displacement of a simply supported beam. $T_{f} / T$ is ratio of first natural period of beam vibration to traveling time.

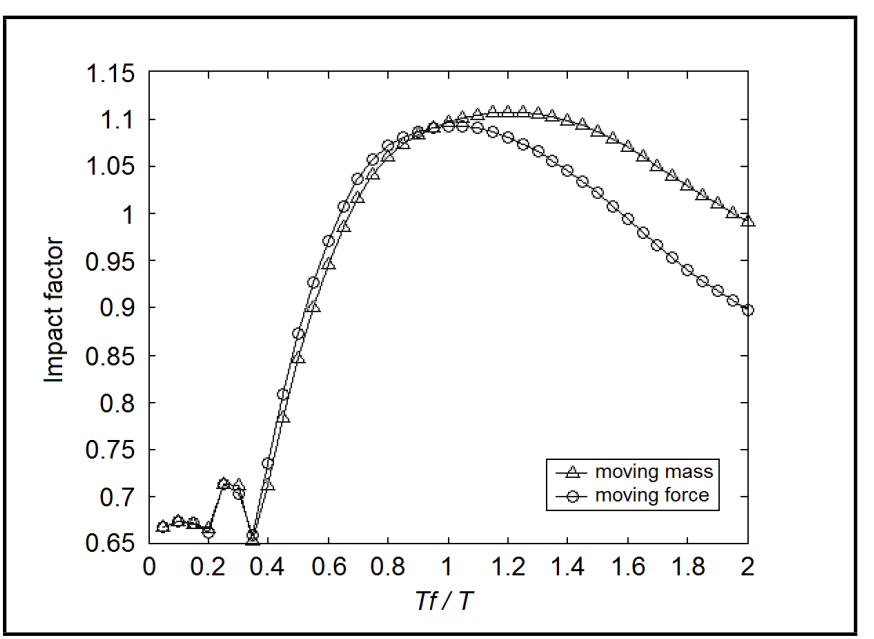

Figure 20. Impact factor for the central displacement of a clamped beam. $T_{f} / T$ is ratio of first natural period of beam vibration to traveling time.

investigated. The effects of variation of a cross-section and moving load parameters on the deflection, natural frequencies, and longitudinal stresses of the beam are also investigated. Additionally, the interaction of vehicle body vibration and support structure is considered. The achieved model can be applied for a general variety of such problems by using the efficient solution method implemented for solving governing equations.

The obtained results indicate that using a beam of parabolically varying thickness with a constant weight can decrease the maximum deflection and stresses along the beam while increasing the natural frequencies of the beam, which can be useful in optimizing the design of support structure. The effect of moving mass inertia at high velocity of moving vehicle is also investigated and the findings indicate that the effect of inertia is significant at high speeds.

\section{REFERENCES}

1 Stokes, G. G. L Discussion of a differential equation relating to the breaching of railway bridges, Transaction of the Cambridge Philosophical Society, 85, 707-735, (1949). http://dx.doi.org/10.1017/cbo9780511702259.013

2 Willis, R. Report of the commission appointed to inquire into the application of iron to railway structures, William Clowes and Sons, London, (1949). 


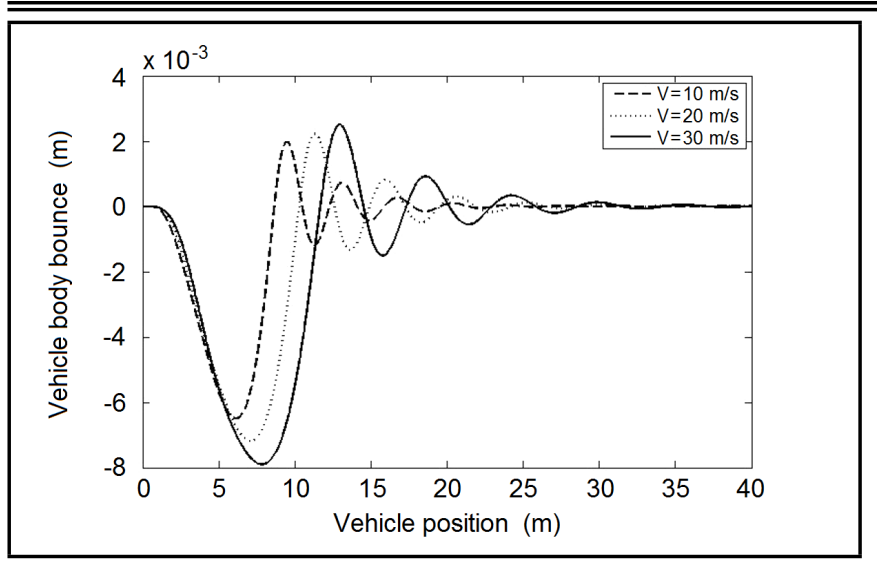

Figure 21. Variation of vehicle body bounce for different vehicle velocities based on half-car model.

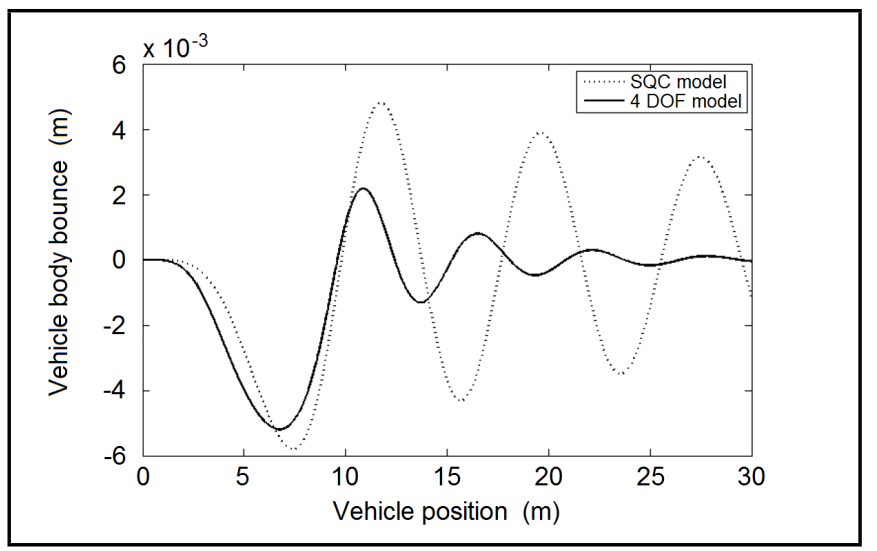

Figure 22. Variation of vehicle body bounce for SQC and 4DOF models.

3 Timoshenko, S., Young D. H., and Weaver, W. Vibration problem in engineering, John Wiley, New York, (1974).

4 Fryba, L. Vibration of solid and structures under moving loads, Groningen, Noordhoff, (1972).

5 Jeffcott, H. H. On the vibration of beams under the action of moving loads, Philosophical Magazine, 48, 66-97, (1929). http://dx.doi.org/10.1080/14786440708564857

6 Akin, J. E. and Mofid, M. Numerical solution for beams with moving mass, Journal of Structural Engineering, 115, 120-131, (1989). http://dx.doi.org/10.1061/(asce)07339445(1989)115:1(120)

7 Esmailzade, E. and Ghorashi, M. Vibration analysis of a Timoshenko Beam subjected to a traveling mass, Journal of Sound and Vibration, 199, 615-628, (1997). http://dx.doi.org/10.1016/s0022-460x(96)99992-7

8 Jalili, N. and Esmailzadeh, E. Dynamic interaction of vehicles moving on uniform bridges, Proceedings of the Institution of Mechanical Engineers, Part K: Journal of Multi-body Dynamics, 216 (4), (2002). http://dx.doi.org/10.1243/146441902320992437

9 Esmailzadeh, E. and Jalili, N. Vehicle-passenger-structure interaction of uniform bridges traversed by moving vehicles, Journal of Sound and Vibration, 260, 611-635, (2003). http://dx.doi.org/10.1016/s0022-460x(02)00960-4

10 Cook, R. D. Concepts and applications of finite element analysis, John Wiley, New York, (2002).

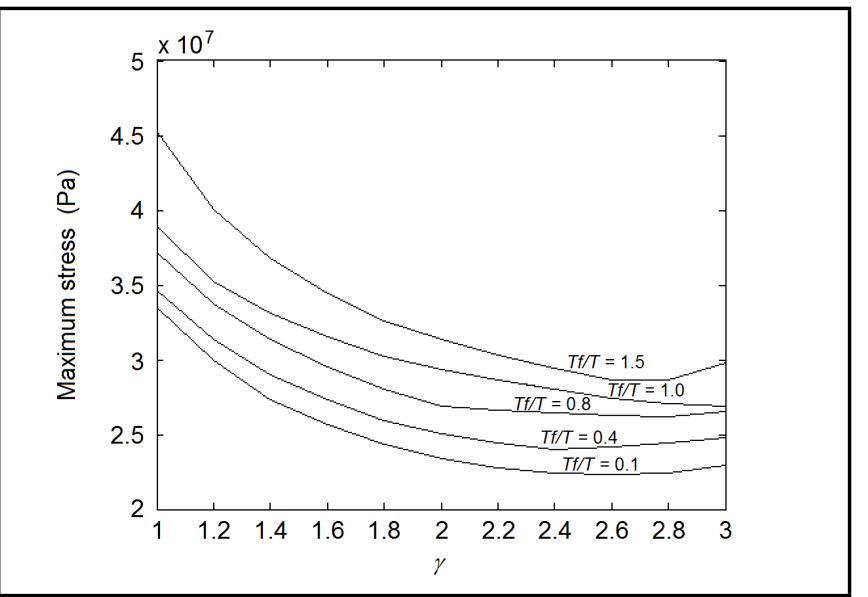

Figure 23. Maximum stress along the simply supported beam versus variation of cross-section profile.

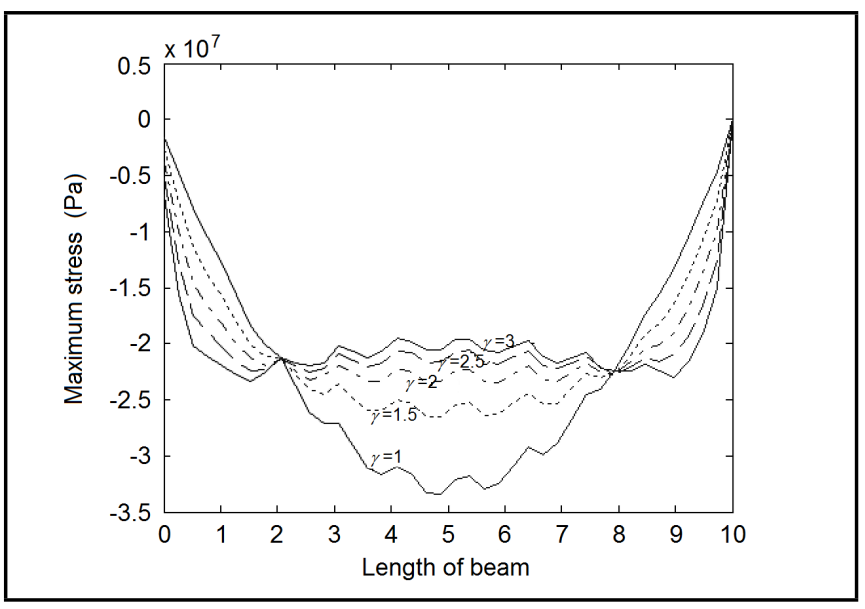

Figure 24. Maximum longitudinal stress at each cross-section along the simply supported beam under moving load.

11 Fleming, J. F. and Romualdi, J. P. Dynamic response of highway bridges, Journal of the Structural Division, 87, 31-61, (1961).

12 Filho, F. V. Finite element analysis of structures under moving loads, Shock and Vibration Digest, 10, 27-35, (1978). http://dx.doi.org/10.1177/058310247801000803

13 Lin, Y. H. and Tretheway, M. W. Finite element analysis of elastic beams subjected to moving dynamic loads, Journal of Sound and Vibration, 136, 323-342, (1990). http://dx.doi.org/10.1016/0022-460x(90)90860-3

14 Gutierrez, R. H. and Laura, A. A. Vibration of a beam of non-uniform cross-section traversed by a time varying concentrated force, Journal of Sound and Vibration, 207 (3), 419-425, (1997). http://dx.doi.org/10.1006/jsvi.1997.1164

15 Gutierrez, R. H. and Laura, A. A. Analysis of vibrating, thin, rectangular plates with point supports by the method of differential quadrature, Ocean Engineering, 22, 101-103, (1995). http://dx.doi.org/doi.org/10.1016/00298018(93)e0001-9

16 Zheng, D. Y., Cheung, Y. K., Au, F. T., and Cheng, Y. S. Vibration of multi-span non-uniform beams under moving loads by using modified beam vibration functions, Journal of Sound and Vibration, 212, 455-467, (1998). http://dx.doi.org/10.1006/jsvi.1997.1435 


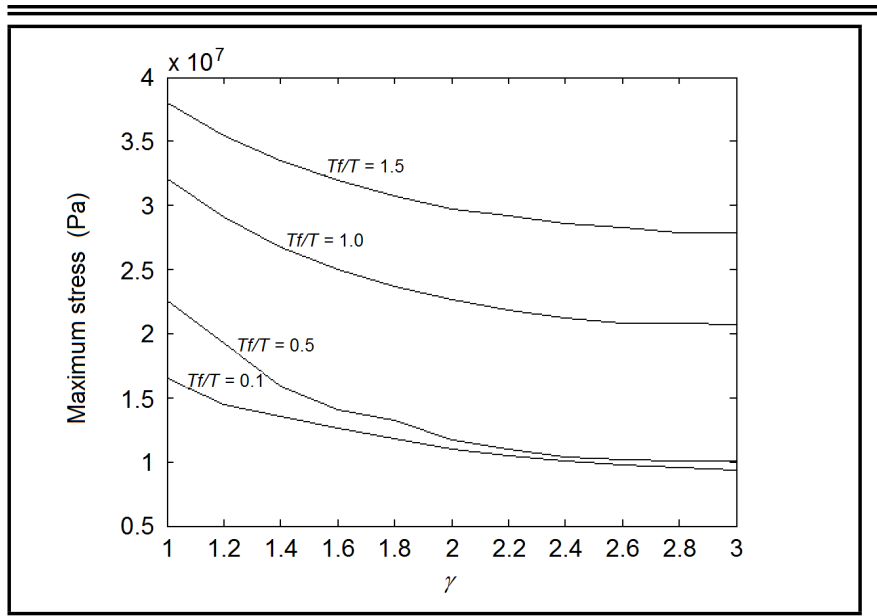

Figure 25. Maximum stress along the clamped beam versus variation of crosssection profile under moving load.

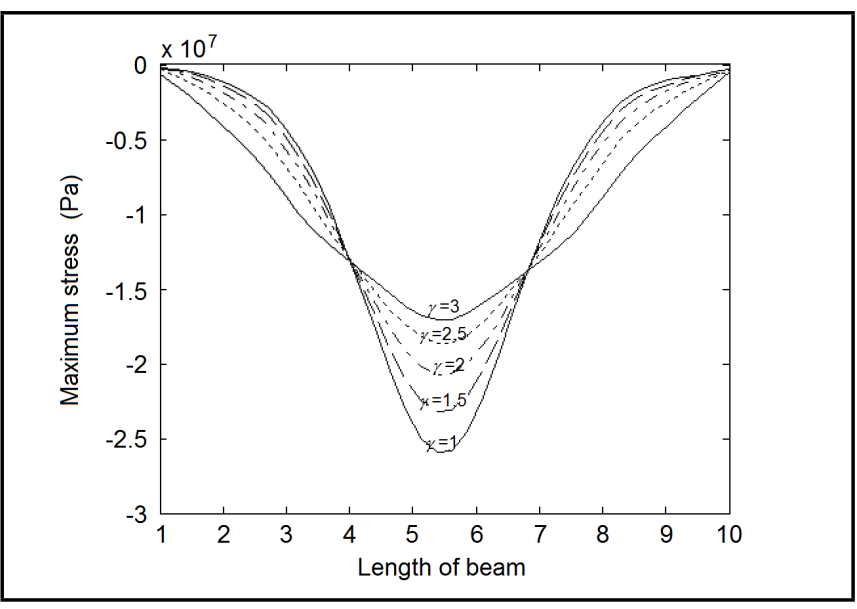

Figure 26. Maximum longitudinal stress at each cross-section along the clamped beam under moving load.

$17 \mathrm{Wu}$, J. S. and Dai, C. W. Dynamic response of multi-span non-uniform beams due to moving loads, Journal of Structural Engineering, 113, 458474, (1987). http://dx.doi.org/10.1061/(asce)07339445(1987)113:3(458)

18 Henchi, K. and Fafard, M. Dynamic behavior of multi-span beams under moving loads, Journal of Sound and Vibration, 199, 33-50, (1997). http://dx.doi.org/10.1006/jsvi.1996.0628

19 Ahmadian, M. T., Esmailzadeh, E., and Asgari, M. Dynamical stress distribution analysis of a non-uniform cross-section beam under moving mass, Proceedings of ASME International Mechanical Engineering Congress and Exposition, Chicago, Illinois, USA, (2006). http://dx.doi.org/10.1115/imece2006-15429

20 Dyniewicz, B. Space-time finite element approach to general description of a moving inertial load, Finite Elements in Analysis and Design, 62, 8-17, (2012). http://dx.doi.org/10.1016/j.finel.2012.07.002

21 Zhai, W. and Song, E. Three dimensional FEM of moving coordinates for the analysis of transient vibrations due to moving loads, Computers and Geotechnics, 37, 164-174, (2010). http://dx.doi.org/10.1016/j.compgeo.2009.08.007

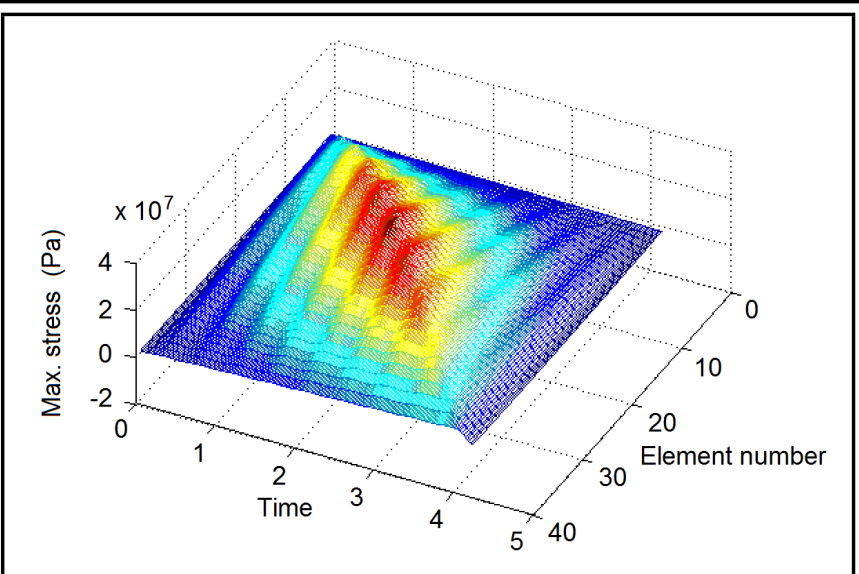

Figure 27. Maximum stresses at each cross-section along a simply supported beam versus load proceeding time for a uniform cross-section.

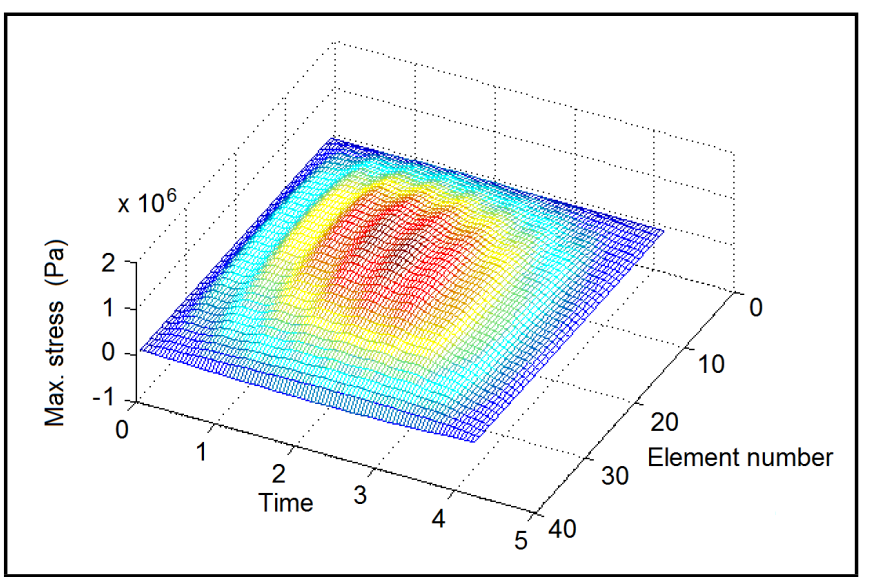

Figure 28. Maximum stresses at each cross-section along a simply supported beam versus load proceeding time for a non-uniform cross-section $(\gamma=2.5)$.

22 Azizi, N., Saadatpour, M. M., and Mahzoon, M. Using spectral element method for analyzing continuous beams and bridges subjected to a moving load, Applied Mathematical Modelling, 36, 3580-3592, (2010). http://dx.doi.org/10.1016/j.apm.2011.10.019

23 Samani, F. S. and Pellicano, F. Vibration reduction of beams subjected to moving loads using linear and nonlinear dynamic absorbers, Journal of Sound and Vibration, 325, 742-754, (2009). http://dx.doi.org/10.1016/j.jsv.2009.04.011

24 Samani, F. S. and Pellicano, F. Vibration reduction of beams under successive traveling loads by means of linear and nonlinear dynamic absorbers, Journal of Sound and Vibration, 331, 2272-2290, (2012). http://dx.doi.org/10.1016/j.jsv.2012.01.002

25 Bathe, J. Finite element procedures in engineering analysis, Englewood Cliffs, Prentice-Hall, New Jersey, (1982).

26 Meirovitch, L. Analytical methods in vibration, McMillan, New York, (1967).

27 Stasa, F. L. Applied finite element for engineers, CBS Publication, (1986).

28 Warburton, G. B. The dynamic behavior of structures, Pergamon Press, Oxford, (1967). 